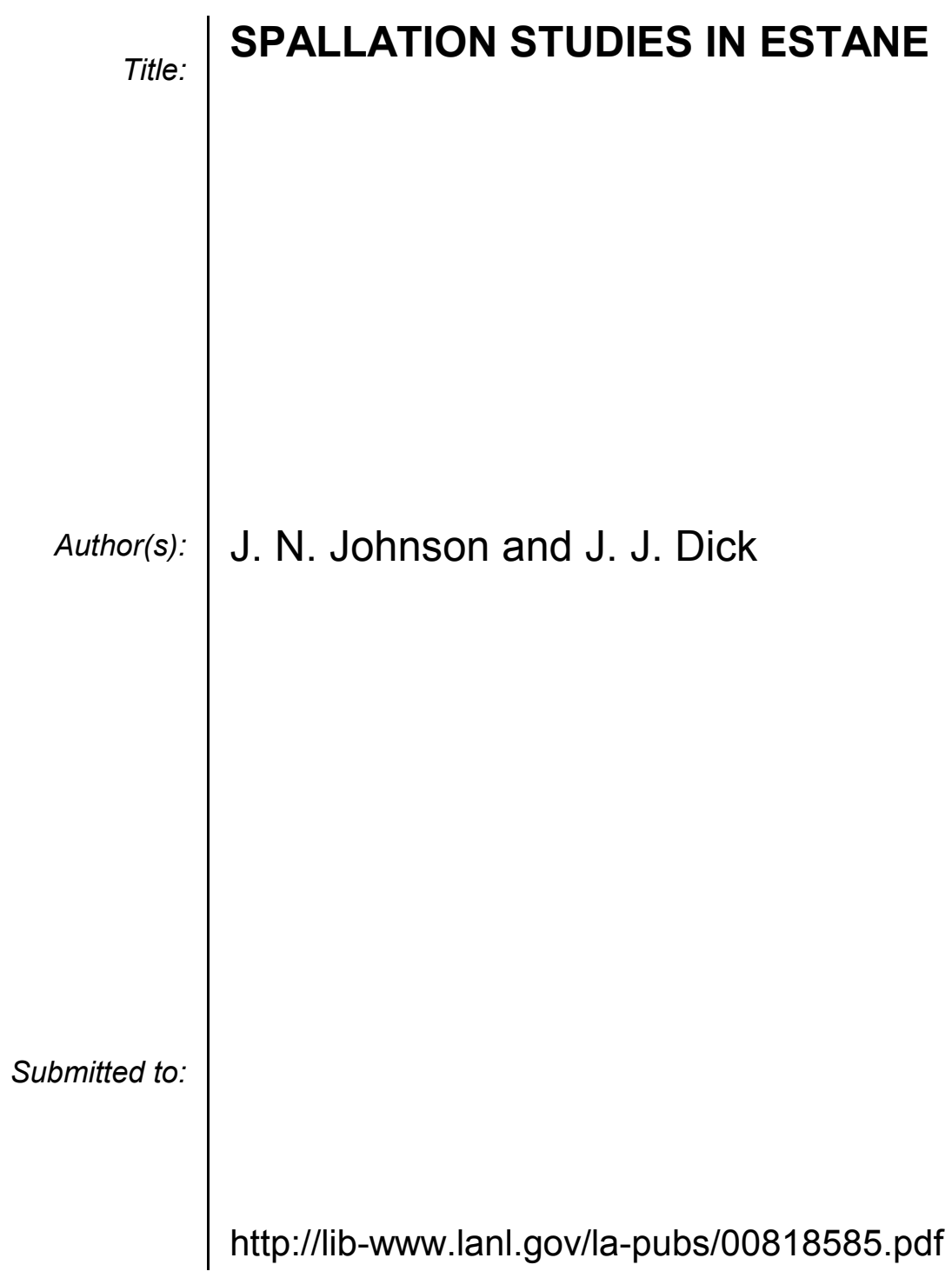

Los Alamos National Laboratory, an affirmative action/equal opportunity employer, is operated by the University of California for the U.S. Department of Energy under contract W-7405-ENG-36. By acceptance of this article, the publisher recognizes that the U.S. Government retains a nonexclusive, royaltyfree license to publish or reproduce the published form of this contribution, or to allow others to do so, for U.S. Government purposes. Los Alamos National Laboratory requests that the publisher identify this article as work performed under the auspices of the U.S. Department of Energy. Los Alamos National Laboratory strongly supports academic freedom and a researcher's right to publish; as an institution, however, the Laboratory does not endorse the viewpoint of a publication or guarantee its technical correctness. 
Paper for proceedings of APS Shock Compression Conference

27 June - 2 July, 1999, Snowbird, Utah

LA-UR-99-2464

\title{
SPALLATION STUDIES IN ESTANE
}

\author{
J. N. Johnson ${ }^{1}$ and J. J. Dick ${ }^{2}$ \\ Los Alamos National Laboratory, Los Alamos, NM 87545 \\ ${ }^{1}$ Theoretical Division \\ 2 Dynamic Experimentation Division
}

\begin{abstract}
Data are presented for the spall fracture of Estane. Estane has been studied previously to determine its low-pressure Hugoniot properties and high-rate viscoelastic response [J.N. Johnson, J.J. Dick and R.S. Hixson, J. Appl. Phys. 84, 2520 - 2529, 1998]. These results are used in the current analysis of spall fracture data for this material. Calculations are carried out with the characteristics code CHARADE and the finite-difference code FIDO. Comparison of model calculations with experimental data show the onset of spall failure to occur when the longitudinal stress reaches approximately $130 \mathrm{MPa}$ in tension. At this point complete material separation does not occur, but rather the tensile strength in the material falls to approximately one-half the value at onset, as determined by CHARADE calculations. Finite-difference calculations indicate that the standard void-growth model (used previously to describe spall in metals) gives a reasonable approximation to the dynamic failure process in Estane. [Research supported by the USDOE under contract W-7405-ENG-36]
\end{abstract}

\section{INTRODUCTION}

The study of dynamic fracture in solids has relied heavily on the spallation test as a means of obtaining information on the time-dependent process of void (or crack) growth, coalescence and material separation. By far, most of the research work on this subject has been directed toward the dynamic fracture of metals and ceramics. The investigation of polymeric materials has been much less studied. A cursory review of the literature shows the existing information on the spall fracture of polymers to consist of the work by Curran, et al . $(1,2)$ on Lexan, a polycarbonate, and Kanel', et al . (3) on rubber.

In the work presented here, experimental studies are undertaken to determine the dynamic spall strength of Estane, a polyurethane, using Z-cut quartz impactors and VISAR free-surface velocity measurement. Model simulations of these experiments are performed with characteristic and finite-difference codes to provide some analysis of the tensile stress states reached, and the approximate kinetics, in the damage accumulation process.

\section{MATERIAL SPECIFICATION AND EXPERIMENTAL TECHNIQUES}

The material studied here is Estane 5703 (manufactured by the B.F. Goodrich Company), a polyester polyurethane elastomer with composition $\mathrm{C}_{5.14} \mathrm{H}_{7.5} \mathrm{~N}_{0.187} \mathrm{O}_{1.76}$ and repeat unit indicated by Gibbs and Popolato (4). Impact samples were hot pressed in vacuum from commercially available flake stock. The initial density of these samples was $1.19 \mathrm{gm} / \mathrm{cm}^{3}$.

Shock-wave experiments were performed using a 72-mm-diam gas gun. The projectile velocity was measured by five shorting pins spaced $10 \mathrm{~mm}$ apart. Projectile tilt was measured with piezoelectric pins surrounding the target disk. Experimental tilts were typically $1.0-1.5 \mathrm{mrad}$, and impact velocities in the two spall tests were $295 \mathrm{~m} / \mathrm{s}$ (shot 1135) and $288 \mathrm{~m} / \mathrm{s}$ (shot 1137). Estane target thicknesses were $3.2 \mathrm{~mm}$ and Z-cut quartz impactor thicknesses were $3.0 \mathrm{~mm}$ in both cases. The nominal longitudinal peak compressive stress in these tests was 800 MPa. 
Shock-release profiles were measured using laser interferometry with a push/pull VISAR system (5). The VISAR records were referenced to the time of impact measured by piezoelectric pins in order to provide accurate determination of shock speed in the target. Figure 1 shows the results of the two spall experiments and the essential reproducibility of the measured material response.

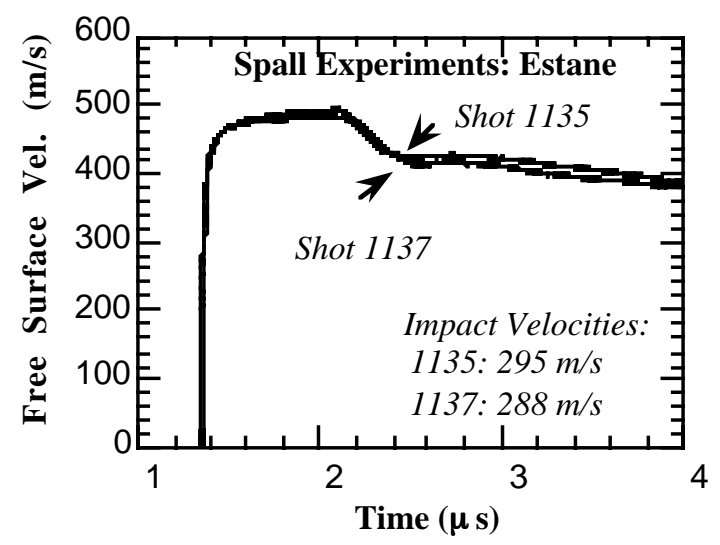

Figure 1. Results of two, nearly identical spall tests in Estane.

\section{CALCULATIONS}

Simulations of spall behavior in Estane are carried out with two one-dimensional wave propagation codes; CHARADE (6) and FIDO. CHARADE is a characteristics code that has been used extensively to describe the non-steady response of rate-dependent materials subject to plate-impact conditions. FIDO is a finite-difference code that is a descendent of that used previously in computer simulations of void growth and spall in copper (7).

CHARADE has recently been used to analyze wave-profile data for Estane, Adiprene, and an Estane/Nitroplasticized polymer (8). Simple tensile fracture simulations are performed with CHARADE, using previously determined viscoelastic behavior, to give an idea of the tensile stress involved at the onset of failure and subsequently. It can be seen from Figure 1 that release from the shocked state proceeds from a plateau velocity of approximately $500 \mathrm{~m} / \mathrm{s}$ to 420 $\mathrm{m} / \mathrm{s}$ before the effect of material spall failure is apparent. This corresponds to a rate-independent onset of spall damage of approximately $130 \mathrm{MPa}$ in tension. Two simulations are performed with the CHARADE code: [1] simple tensile failure at -130
MPa immediately followed by a complete loss of strength; and [2] tensile failure at a threshold of $130 \mathrm{MPa}$ with the longitudinal stress component thereafter remaining constant at a residual value of $130 \mathrm{MPa}$. These two results are shown in Figure 2.

Neither of these assumptions comes close to representing the data of Figure 1. An inter-

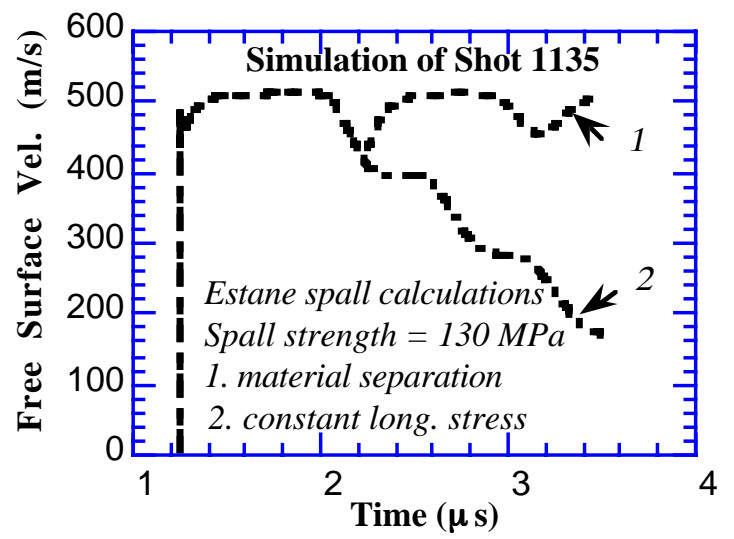

Figure 2. CHARADE simulation of shot 1135: [1] complete material separation at tensile stress of $-130 \mathrm{MPa}$ : [2] tensile threshold stress of $-130 \mathrm{MPa}$ at spall plane followed by constant residual strength of $-130 \mathrm{MPa}$.

mediate condition of a $-130 \mathrm{MPa}$ threshold with a $65 \mathrm{MPa}$ residual stress is then calculated and compared with the data. This result is shown in Figure 3. The agreement between theory and experiment becomes more reasonable except for the "ringing" that is observed in the calculated spall signal. This likely means that the loss of strength in failure of Estane is more gradual than represented by the various thresholds and instantaneous adjustment to a lower residual stress used in these calculations.

Characteristic calculations give the stress and particle velocity at a common spatial location at time $t+\Delta t$ from information at time $t$. Internal state variables, such as porosity in the case of a spalling ductile solid, for example, are then calculated subsequently. Hence, characteristic codes are useful in rate-dependent spall calculations only if one is prepared to reduce the hydrodynamic time increment to a very small value required by the void-growth process. Finite-difference calculations, on the other hand, permit subcycling on internal-state-variable evolution driven by a nearly constant strain rate over the time increment $\Delta t$. 


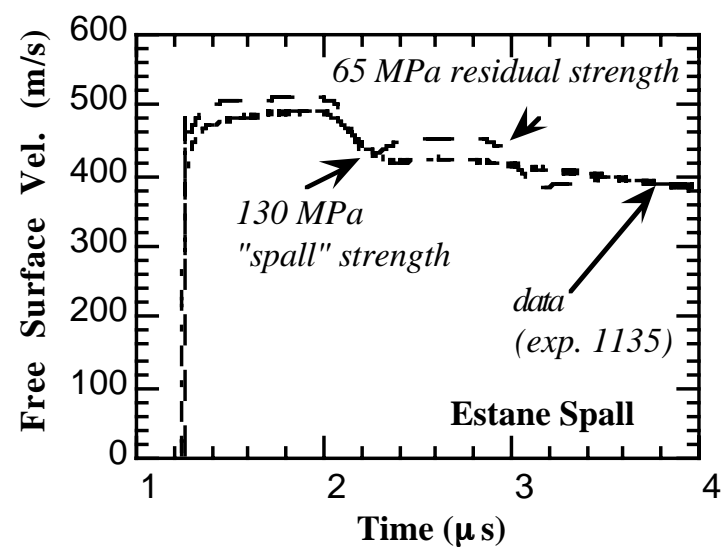

Figure 3. CHARADE simulation of shot 1135. "Spall strength" of $130 \mathrm{MPa}$ followed by constant residual strength of $65 \mathrm{MPa}$.

For this reason we choose to calculate the spall properties of Estane using a finite-difference code (FIDO) with a previously developed void-growth model that has been successful in describing failure in metals. We retain the viscoelastic property description of Estane (8), but simply apply an existing void-growth model (7) for the development of spall damage. The presence of voids is expressed in terms of a distention ratio $\alpha$, which is related to the porosity $\varphi$ according to $\varphi=1-1 / \alpha$. In the absence of inertial effects, the rate of change of $\alpha$ is given by

$$
\begin{gathered}
\dot{\alpha}=0, \quad \Delta p \geq 0 \\
\dot{\alpha}=-\frac{\left(\alpha_{0}-1\right)^{2 / 3}}{\eta} \alpha(\alpha-1)^{1 / 3} \Delta p, \\
\Delta p<0
\end{gathered}
$$

where $\Delta p$ is the driving stress for void growth as given by

$$
\Delta p=p+\frac{a_{S}}{\alpha} \ln \left(\frac{\alpha}{\alpha-1}\right)
$$

Here $\eta$ is a material parameter with units of stress $\times$ time and $a_{s}$ controls the threshold for void growth (units of stress). The parameter $\alpha_{0}$ provides the initial distention to get the void-growth process started and can be thought of as an initiation term. The variable $p$ is the average mean stress in the porous region containing voids.

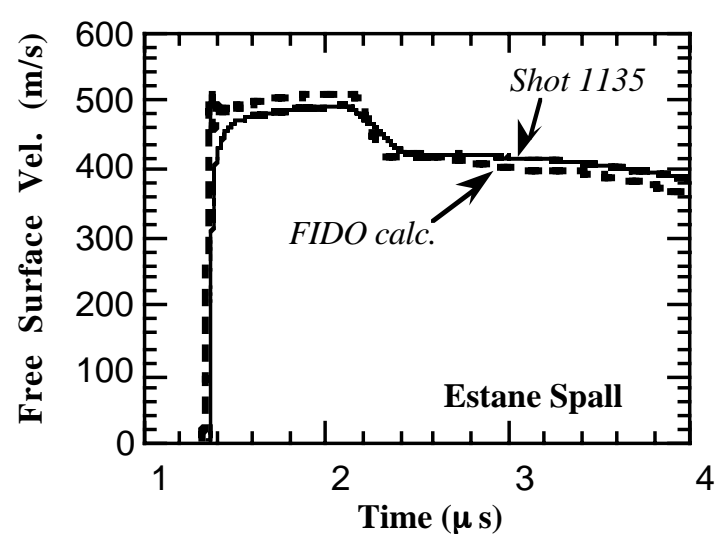

Figure 4. FIDO void-growth model calculation in comparison with spall data for Estane.

Calculations with viscoelastic properties and equation of state information provided in reference 8 along with material void-growth parameters $\alpha_{0}=1.0015, a_{s}=10 \mathrm{MPa}$, and $\eta=1 \mathrm{MPa} \cdot \mu \mathrm{s}$ are shown in Figure 4 along with the data from shot 1135 (Figure 1).

The actual viscoelastic description used in the finite-difference calculations of Figure 4 is somewhat simplified from that given in reference 8 . The bulk response differs slightly, with a zeropressure bulk sound speed of $1.75 \mathrm{~mm} / \mu \mathrm{s}$ and shock-velocity/particle-velocity slope of 2.2. Viscoelastic behavior is contained in the deviatoric response according to the following set of equations applicable to high-strain rates:

$$
\begin{gathered}
\dot{s}_{i j}=2 G \dot{e}_{i j}-\frac{s_{i j}-r_{i j}\left(e_{i j}\right)}{\tau} \\
r_{i j}=2 G_{r} e_{i j}
\end{gathered}
$$

where $e_{i j}$ is the strain deviator, $s_{i j}$ is the stress deviator and $r_{i j}$ is a "relaxed" stress deviator, i.e., that toward which $s_{i j}$ would relax at low strain rates (rates lower than those achieved under impact conditions). The material parameters in Eqs. (4) and (5) for Estane are $G=34 \mathrm{MPa}, G_{r}=4 \mathrm{MPa}$, and $\tau$ $=200 n s$. The simplification of Eqs. (4) and (5) over the viscoelastic description used previously is that the former description accurately represents viscoelastic response in the low-to-intermediate strain-rate regime, while the above set of equations does not. 
The results shown in Figure 4 illustrate several key features related to spall fracture of Estane. The first is that the threshold for void growth, calculated from Eq. (3), is $65 \mathrm{MPa}$, in good agreement with the rate-independent residual stress threshold used in the CHARADE calculation of Figure 3. The second is that void-growth kinetics automatically provide the gradual loss of material strength at the spall plane that is reflected in the VISAR signal of experiment 1135 . The good agreement between simulation and experiment may be fortuitous in view of the fact that the void-growth model was developed for elastic-plastic materials with constant yield strength. Nevertheless, it is apparent that a simple void-growth description gives a reasonable description of the time-dependent spallation process in Estane.

\section{SUMMARY}

In this paper we have brought together a number of important measurements and models that combine to give a reasonable description of spall fracture in Estane. First is the viscoelastic response of Estane and equation of state information as reported in reference 8 . Second is the void-growth description, initially developed for elastic-plastic solids, expressed in terms of an initial volume distention, threshold stress, and rate parameter (reference 7). Finally, we have new spall fracture data for Estane as shown in Figure 1. Combination of these models and data show that elementary considerations lead to a reasonably accurate model for spall fracture in this material. The rate-dependent threshold for failure is approximately $65 \mathrm{MPa}$ in tension, and the rate of damage accumulation is controlled by the rate parameter $\eta$, whose nominal value for Estane is approximately the same as that for copper (reference 7), $1 M P a \cdot \mu s$. The initial porosity of 0.0015 is considerably greater than that used for metal spall $(\approx 0.0003)$, and perhaps simply represents a lower threshold for nucleation of voids in polymeric materials.

Several ideas present themselves for improvement of model representations of spall failure in polymers. The first is to replace the voidgrowth description used here with a corresponding description based on void growth in a purely viscoelastic material. Clements (9) has been working on such a description, not only for spherical void growth, but also for elliptically shaped voids. Second, it would be extremely useful to have recovery experiments that provide direct observation of the damaged region in spalled polymers. This may be difficult because of the inherent low strength of these materials and their inelastic recovery following permanent deformation, but such data would definitely help to more fully establish the micromechanical deformation process in polymers as it has done so well for elastic-plastic and brittle materials.

\section{ACKNOWLEDGMENTS}

The authors gratefully acknowledge financial support for this work from the Joint DoD/DOE Munitions Technology Development Program and the (LANL) Laboratory Directed Research and Development project on polymer aging.

\section{REFERENCES}

1. Curran, D. R., Seaman, L., and Shockey, D. A., Phys. Today 30, 46 - 55 (1977).

2. Curran, D.R., Shockey, D.A., and Seaman, L., J. Appl. Phys. 44, 4025 - 4038 (1973).

3. Kanel', G. I., Razorenov, S. V., and Utkin, A V., "Spallation in Solids Under Shock-Wave Loading: Analysis of Dynamic Flow, Methodology of Measurements, and Constitutive Factors," in HighPressure Shock Compression of Solids II, edited by L. Davison, D.E. Grady, and M. Shahinpoor, Springer, New York, 1989, pp. 1 - 24.

4. Gibbs T. R. and Popalato, A., LASL Explosive Property Data, University of California Press, Berkeley, 1980, p. 110.

5. Hemsing, W. F., Rev. Sci. Instrum. 50, 73 - 78 (1979).

6. Johnson, J. N. and Tonks, D L., "CHARADE: A Characteristic Code for Calculating Rate-Dependent Shock-Wave Response," Los Alamos National Laboratory Report LA-11993-MS (January 1991).

7. Johnson, J. N., J. Appl. Phys. 52, 2812 - 2825 (1981).

8. Johnson, J. N., Dick, J. J., and Hixson, R. S., J. Appl. Phys. 84, 2520 - 2529 (1998).

9. Clements, B. E., personal communication (1999). 